\title{
Controversy in the treatment of symptomatic internal rectal prolapse: suspension or resection?
}

\author{
S. Festen · A. A. W. van Geloven · A. D'Hoore • \\ I. Lindsey $\cdot$ M. F. Gerhards
}

Received: 6 November 2010/Accepted: 9 November 2010/Published online: 8 December 2010

(c) The Author(s) 2010. This article is published with open access at Springerlink.com

Internal rectal prolapse (IRP) is a full-thickness intussusception of the rectum during defecation. Radiologically, different grades have been proposed: from low-grade (rectorectal intussusception) to high-grade (rectoanal intussusception) prolapse. This prolapse may lead to an outlet obstruction and/or fecal incontinence. IRP plays an important role in the pathophysiology of obstructed defecation (OD), which is the inability to empty the rectum satisfactorily during defecation and is more specifically defined in the Rome III criteria.

There has been debate for decades about the clinical significance of IRP. However, there appears to be a renewed interest in the clinical relevance and treatment of IRP. The long disputed progression into ERP has been made more plausible by recent data published by Wijffels et al. [1] on the natural history of IRP. Moreover, various recent publications on new surgical techniques have shown

\section{S. Festen $(\bowtie)$}

Department of Surgery, Reinier de Graaf Hospital, Reinier de Graafweg 3-11, 2525, AD, Delft, The Netherlands

e-mail: Sebastiaanfesten@yahoo.com

\section{A. A. W. van Geloven}

Department of Surgery, Tergooi Ziekenhuizen, Hilversum, The Netherlands

\section{A. D'Hoore}

Department of Abdominal Surgery, University Clinics

Gasthuisberg, Leuven, Belgium

\section{Lindsey}

Oxford Pelvic Floor Centre, Department of Colorectal Surgery, Churchill Hospital, Headington, Oxford

\section{F. Gerhards}

Department of Surgery, Onze Lieve Vrouwe Gasthuis, Amsterdam, The Netherlands improved functional outcome after prolapse correction compared with historical surgical series. Patient selection however remains critical [2-4].

Surgical correction for IRP is possible via a transabdominal or transanal approach. Currently the most common procedures are laparoscopic ventral rectopexy (LVR) and stapled transanal rectal resection (STARR). LVR corrects the intussusceptions of the rectum and reinforces the rectovaginal septum by the use of a mesh, which suspends the rectum and vaginal vault to the sacral promontory, whereas in the STARR procedure a stapled resection of the redundant rectal wall is performed. Most of the recent publications on IRP and OD are divided between proponents of these two techniques. There are, however, no comparative studies, making it difficult to select the optimal treatment for each individual patient. Therefore, our purpose was to give an overview of the existing data and controversies on these techniques.

\section{Treatment}

Laparoscopic ventral (mesh) rectopexy (LVR) was first described by D'Hoore et al. in 2004 and has gained widespread acceptance [5-7]. The technique is based on correcting the descent of the posterior and middle pelvic compartments combined with reinforcement of the rectovaginal septum. In contrast with previously described posterior rectopexy techniques, in which induction of constipation proved to be a major deterrent, this procedure limits the chance of damaging the autonomous nerves by avoiding posterolateral rectal dissection. The initial papers reported favorable functional results in treating patients with an ERP [2]. These good results in treating ERP by LVR have been confirmed by others [8, 9]. Recently data 
have become available on the results of this procedure in patients with symptomatic high-grade IRP. Reports by Collinson et al. and Slawik et al. have shown similar functional improvement in the short- and medium-term, with improvement in constipation in approximately $80 \%$ of patients with almost no new onset constipation and acceptably low recurrence rates (approximately 5\%) [4, 6]. A recent meta-analysis on ventral rectopexy, with or without posterior dissection, for IRP and ERP, concluded that there is a greater reduction in postoperative constipation if no posterior dissection is performed [10].

Instead of correcting the descent of the pelvic compartments, the STARR resects redundant tissue. Moreover, reduced rectal sensitivity is improved as shown on postoperative manometry [11]. The original technique was derived from the procedure for prolapse and hemorrhoids $(\mathrm{PPH})$, using the same stapling device (PPH01, Ethicon EndoSurgery, Cincinnati, OH). Recently this technique has been refined with the development of the Contour ${ }^{\circledR}$ Transtar $^{\mathrm{TM}}$ stapler (Ethicon EndoSurgery), resulting in a further controlled full-thickness resection of even more tissue.

The rate of improvement after both techniques ranges from 56 to $95 \%$ at short- and medium-term follow-up [11-13], with more recent studies claiming a fairly consistent success rate of approximately $80 \%$ [3, 14, 15]. Although there are reports of serious complications after STARR [16], most large series show a low and acceptable morbidity rate.

\section{Discussion}

When comparing the transabdominal and transanal route of surgery, it is clear that both techniques hinge on a different theoretical basis. One could argue that LVR corrects the leading cause (the rectal intussusceptions) of the symptoms, whereas STARR only treats its consequences. In addition, LVR makes correction of coexisting prolapse of the middle pelvic compartment, an enterocoele or vaginal descent, possible. Conversely, STARR has been shown to improve the rectal sensitivity, as has been confirmed objectively by anal manometry. In one report this increased sensitivity was significantly correlated with higher patient satisfaction [17]. STARR certainly reduces the rectal capacity and possibly hereby the rectal sensitivity, but the final consequences on fecal continence are still unknown. Transient urgency and urgency incontinence have been described to occur in approximately $15-47 \%$ of patients after STARR, which can persist for up to 12 months in approximately $10 \%$ [3, 11, 17, 18]. In most patients, however, urgency is reported to be a self-limiting symptom [18]. It is difficult to determine the role of rectal sensitivity after LVR, because almost no studies have reported on volumetry and manometry values before and after LVR. One study, however, has reported on rectal manometry after LVR for complex rectoceles, showing no significant decrease of rectal capacity or compliance [19].

Although short- and medium-term success rates of both techniques have proved to be comparable, long-term results are still awaited. It can be hypothesized that IRP is a precursor stage of ERP. In ERP, resectional therapy has been shown to have high recurrence rates in contrast to rectopexy [20-23]. If we extrapolate this to the results after LVR and STARR in the treatment of IRP, it is perhaps reasonable to expect a better long-term outcome after LVR. However, because these data are not yet available, other factors have to be taken into account when choosing one surgical technique compared with the other.

Another reason to choose one technique over another is the risk of morbidity. Constipation after LVR may constitute the counterpart of fecal urgency after STARR. Although D'Hoore et al. found no worsening or new onset of constipation in their patients [5], some studies have reported its occurrence to be $15-50 \%$ [10]. On the contrary, although constipation is not reported after STARR, it may induce fecal incontinence (FI). Stretching of the anal sphincter muscle during the procedure and postoperative fecal urgency (reduction of rectal compliance properties), threatening marginal sphincters, are two potential causative factors. Therefore, some authors advise avoidance of STARR for patients with already impaired sphincter function. Moreover, symptoms of OD may mask coexisting FI, which only becomes apparent after successful treatment of OD. In contrast, it is believed that STARR in itself can relieve symptoms of incontinence by correction of rectoanal intussusception, eliminating the sphincter-impairing obstruction of the anal canal. Even though not all studies report postoperative incontinence rates after STARR, the papers that do report a low incidence and spontaneous resolution in the long-term $[17,18]$.

Apart from the above-mentioned functional complications, both techniques have procedure-specific complications. Various reports describe stapler-line dehiscence, rectal necrosis, and even rectovaginal fistula after STARR [13]. STARR proponents claim that these complications are anecdotal, although the true incidence is not known. Some authors attribute these complications to a steep learning curve-the reason that surgeons are now only allowed to perform STARR after a company-initiated training and proctorship. On the contrary, LVR has a relatively low risk of laparoscopy-related complications, such as port site hernia, port site hematoma, and inadvertent bowel perforation and procedure-specific, mesh-related complications, which have been reported rarely but can have serious consequences [7]. Moreover, to be able to perform LVR, the surgeon must have substantial 
experience in laparoscopic colorectal surgery, but even then there appears to be a continuing learning curve concerning operation time [5, 7]. Although not reported, the learning curve might influence the functional outcome after LVR.

One important difficulty in comparing data of both treatment modalities is the variability of used parameters and lack of clarity in patient selection. Not all potentially relevant factors are analyzed pre- and post-operatively in most studies. For instance, almost none of the LVR papers report on the coexistence of a rectocele in their patients with IRP, whereas in the group of patients treated with a stapling technique, almost all patients had a rectocele. Is this a matter of patient selection, or are rectoceles just not documented in the LVR studies? Probably it is mentioned in STARR procedures because in this treatment a rectocele is considered to be redundant rectal tissue, whereas it is considered physiological or the sequela of prolapse by those who perform LVR. The use of a universal, validated, disease-specific, symptom-based scoring system, such as the one proposed by Altomare et al. [24], is mandatory in comparing functional treatment outcomes.

Is it possible with the available evidence to design a treatment algorithm for patients with OD and IRP? A decision-making algorithm for the STARR procedure is already developed [25], but would it not be better to have a disease-based algorithm, irrespective of the treatment modality? In our opinion, symptomatic IRP and FI needs to be distinguished from IRP associated with OD. A highgrade prolapse giving rise to sphincter dysfunction and fecal incontinence should be considered a close precursor of ERP and therefore be treated, probably with LVR, to prevent further sphincter deterioration.

When IRP is associated with OD, choosing treatment becomes more difficult. Until long-term follow-up data on function and recurrence are available, it is up to the surgeon to choose between a transanal stapled procedure and LVR in an uncomplicated patient with IRP with (or, in the unusual case, without) a rectocele. However, in the complicated patient with a fixed enterocele or sigmoidocele, a STARR is contraindicated. In addition, one can correct these coexisting conditions that may contribute to the OD during the same procedure when doing a LVR. Also, in the patient with a concomitant prolapse of the vagina, a LVR is preferred, because a correction of the descent of the middle pelvic compartment is feasible. Finally, in a patient with compromised anal sphincter function, we believe that it is better to avoid transanal procedures to prevent worsening of these symptoms. On the other hand, if a patient has sustained severe pelvic inflammation in the past, has undergone several abdominal surgical procedures, or has substantial comorbidity contraindicating a laparoscopy, it may be better to perform a stapled transanal procedure.

\section{Conclusions}

Surgical decision-making for OD remains difficult and complex. Even more important than surgical technical skills is the surgeon's experience and the understanding of pelvic anatomy and pathophysiology. Preoperative functional investigation and the use of an objective scoring system should improve selection of patients who would benefit from surgery. Furthermore, assessment of the functional outcome (and new onset functional sequelae) is more important than the evaluation of the anatomic result. The success of surgery is not dictated only by choosing between a transabdominal and a transanal route. To be able to offer these patients a tailored approach, a colorectal surgeon who is specialized in pelvic floor pathology should be able to perform both techniques.

Disclosures Dr. Festen, Dr. van Geloven, Prof. D’Hoore, Dr. Lindsey, and Dr. Gerhards have no conflicts of interest or financial ties to disclose.

Open Access This article is distributed under the terms of the Creative Commons Attribution Noncommercial License which permits any noncommercial use, distribution, and reproduction in any medium, provided the original author(s) and source are credited.

\section{References}

1. Wijffels NA, Collinson R, Cunningham C, Lindsey I (2010) What is the natural history of internal rectal prolapse? Colorectal Dis 12:822-830

2. D'Hoore A, Penninckx F (2006) Laparoscopic ventral recto(colpo)pexy for rectal prolapse: surgical technique and outcome for 109 patients. Surg Endosc 20:1919-1923

3. Lenisa L, Schwandner O, Stuto A, Jayne D, Pigot F, Tuech JJ, Scherer R, Nugent K, Corbisier F, Espin-Basany E, Hetzer FH (2009) STARR with Contour Transtar: prospective multicentre European study. Colorectal Dis 11:821-827

4. Collinson R, Wijffels N, Cunningham C, Lindsey I (2010) Laparoscopic ventral rectopexy for internal rectal prolapse: shortterm functional results. Colorectal Dis 12:97-104

5. D'Hoore A, Cadoni R, Penninckx F (2004) Long-term outcome of laparoscopic ventral rectopexy for total rectal prolapse. $\mathrm{Br}$ J Surg 91:1500-1505

6. Slawik S, Soulsby R, Carter H, Payne H, Dixon AR (2008) Laparoscopic ventral rectopexy, posterior colporrhaphy and vaginal sacrocolpopexy for the treatment of recto-genital prolapse and mechanical outlet obstruction. Colorectal Dis 10:138-143

7. van den Esschert JW, van Geloven AA, Vermulst N, Groenedijk AG, de Wit LT, Gerhards MF (2008) Laparoscopic ventral rectopexy for obstructed defecation syndrome. Surg Endosc 22:2728-2732

8. Boons P, Collinson R, Cunningham C, Lindsey I (2010) Laparoscopic ventral rectopexy for external rectal prolapse improves constipation and avoids de novo constipation. Colorectal Dis $12: 526-532$

9. Wijffels N, Cunningham C, Dixon A, Greenslade G, Lindsey I (2010) Laparoscopic anterior rectopexy for external rectal 
prolapse is safe and effective in the elderly. Does this make perineal procedures obsolete? Colorectal Dis (in press)

10. Samaranayake CB, Luo C, Plank AW, Merrie AE, Plank LD, Bissett IP (2010) Systematic review on ventral rectopexy for rectal prolapse and intussusception. Colorectal Dis 12:504-512

11. Boccasanta P, Venturi M, Salamina G, Cesana BM, Bernasconi F, Roviaro G (2004) New trends in the surgical treatment of outlet obstruction: clinical and functional results of two novel transanal stapled techniques from a randomised controlled trial. Int J Colorectal Dis 19:359-369

12. Dodi G, Pietroletti R, Milito G, Binda G, Pescatori M (2003) Bleeding, incontinence, pain and constipation after STARR transanal double stapling rectotomy for obstructed defecation. Tech Coloproctol 7:148-153

13. Gagliardi G, Pescatori M, Altomare DF, Binda GA, Bottini C, Dodi G, Filingeri V, Milito G, Rinaldi M, Romano G, Spazzafumo L, Trompetto M (2008) Results, outcome predictors, and complications after stapled transanal rectal resection for obstructed defecation. Dis Colon Rectum 51:186-195

14. Jayne DG, Schwandner O, Stuto A (2009) Stapled transanal rectal resection for obstructed defecation syndrome: one-year results of the European STARR Registry. Dis Colon Rectum 52:1205-1212

15. Renzi A, Talento P, Giardiello C, Angelone G, Izzo D, Di SG (2008) Stapled trans-anal rectal resection (STARR) by a new dedicated device for the surgical treatment of obstructed defaecation syndrome caused by rectal intussusception and rectocele: early results of a multicenter prospective study. Int J Colorectal Dis 23:999-1005

16. Pescatori M, Gagliardi G (2008) Postoperative complications after procedure for prolapsed hemorrhoids $(\mathrm{PPH})$ and stapled transanal rectal resection (STARR) procedures. Tech Coloproctol 12:7-19
17. Reboa G, Gipponi M, Logorio M, Marino P, Lantieri F (2009) The impact of stapled transanal rectal resection on anorectal function in patients with obstructed defecation syndrome. Dis Colon Rectum 52:1598-1604

18. Titu LV, Riyad K, Carter H, Dixon AR (2009) Stapled transanal rectal resection for obstructed defecation: a cautionary tale. Dis Colon Rectum 52:1716-1722

19. D'Hoore A, Vanbeckevoort D, Penninckx F (2008) Clinical, physiological and radiological assessment of rectovaginal septum reinforcement with mesh for complex rectocele. $\mathrm{Br} \mathrm{J}$ Surg 95:1264-1272

20. Altemeier WA, Culbertson WR, Schowengerdt C, Hunt J (1971) Nineteen years' experience with the one-stage perineal repair of rectal prolapse. Ann Surg 173:993-1006

21. Blatchford GJ, Perry RE, Thorson AG, Christensen MA (1989) Rectopexy without resection for rectal prolapse. Am J Surg 158:574-576

22. Friedman R, Muggia-Sulam M, Freund HR (1983) Experience with the one-stage perineal repair of rectal prolapse. Dis Colon Rectum 26:789-791

23. Loygue J, Huguier M, Malafosse M, Biotois H (1971) Complete prolapse of the rectum. A report on 140 cases treated by rectopexy. Br J Surg 58:847-848

24. Altomare DF, Spazzafumo L, Rinaldi M, Dodi G, Ghiselli R, Piloni V (2008) Set-up and statistical validation of a new scoring system for obstructed defaecation syndrome. Colorectal Dis $10: 84-88$

25. Schwandner O, Stuto A, Jayne D, Lenisa L, Pigot F, Tuech JJ, Scherer R, Nugent K, Corbisier F, Basany EE, Hetzer FH (2008) Decision-making algorithm for the STARR procedure in obstructed defecation syndrome: position statement of the group of STARR Pioneers. Surg Innov 15:105-109 